\title{
Eosinophilic pleural effusion due to lung cancer has a better prognosis than non-eosinophilic malignant pleural effusion
}

\author{
Eiji Takeuchi ${ }^{1}$ (1) $\cdot$ Yoshio Okano $^{2} \cdot$ Hisanori Machida $^{2} \cdot$ Katsuhiro Atagi $^{2} \cdot$ Yoshihiro Kondou $^{2} \cdot$ Naoki Kadota $^{2} \cdot$ \\ Nobuo Hatakeyama ${ }^{2} \cdot K_{\text {Keishi Naruse }}^{3} \cdot$ Tsutomu Shinohara $^{4}$
}

Received: 14 May 2021 / Accepted: 19 June 2021 / Published online: 25 June 2021

(c) The Author(s) 2021

\begin{abstract}
Objective Tumor-related eosinophilia may have extended survival benefits for some cancer patients. However, there has been no report on the prognosis difference between eosinophilic pleural effusion (EPE) and non-EPE in lung cancer patients. Our study aimed to investigate the prognosis difference between EPE and non-EPE due to lung cancer.

Patients and methods We retrospectively reviewed patients diagnosed with lung cancer who presented with malignant pleural effusion (MPE) between May 2007 and September 2020 at the National Hospital Organization Kochi Hospital. EPE is defined as pleural fluid with a nucleated cell count containing $10 \%$ or more eosinophils.

Results A total of 152 patients were included: 89 were male (59\%). The median age was 74.4 years (range 37-101), and all patients were pathologically shown to have MPE. Most patients (140; 92\%) had an Eastern Cooperative Oncology Group (ECOG) Performance Status (PS) of 0/1. Twenty patients had EPE. The median overall survival (OS) of all 152 lung cancer patients with MPE was 298 days. The median OS of the patients with EPE was 766 days, and the median OS of the patients with non-EPE was 252 days. Kaplan-Meier univariate analysis showed that lung cancer patients with EPE had a significantly better prognosis than patients with non-EPE $(\mathrm{P}<0.05)$. Cox proportional regression analysis showed that EPE, ECOG PS, sex, and the neutrophil-to-lymphocyte ratio in the serum (sNLR) may be independent prognostic factors affecting survival in patients with MPE.
\end{abstract}

Conclusion Lung cancer patients with EPE have a better prognosis than those with non-EPE.

Keywords Lung cancer $\cdot$ Malignant pleural effusion $\cdot$ Eosinophilic pleural effusion $\cdot$ Survival $\cdot$ Better prognosis

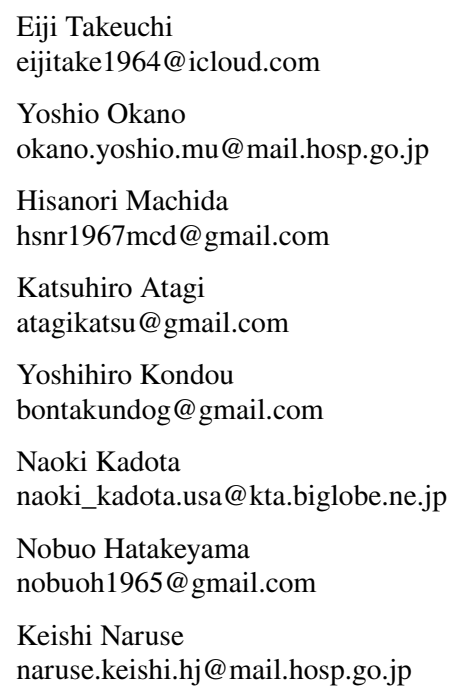

Tsutomu Shinohara

shinohara_fau@yahoo.co.jp

1 Department of Clinical Investigation, National Hospital Organization Kochi Hospital, 1-2-25 Asakuranishimachi, Kochi-city, Kochi 780-8507, Japan

2 Department of Respiratory Medicine, National Hospital Organization Kochi Hospital, 1-2-25 Asakuranishimachi, Kochi-city, Kochi 780-8507, Japan

3 Department of Pathology, National Hospital Organization Kochi Hospital, 1-2-25 Asakuranishimachi, Kochi-city, Kochi 780-8507, Japan

4 Department of Community Medicine for Respirology, Graduate School of Biomedical Sciences, Tokushima University, 3-18-15 Kuramoto-cho, Tokushima 770-8503, Japan 


\section{List of symbols}

ALK : Anaplastic lymphoma kinase

CI : Confidence interval

ECOG : Eastern Cooperative Oncology Group

EGFR : Epidermal growth factor receptor

EPE : Eosinophilic pleural effusion

IL : Interleukin

ILC2 : Group 2 innate lymphoid cells

MPE : Malignant pleural effusion

OS : Overall survival

PS : Performance Status

sNLR : Neutrophil-to-lymphocyte ratio in the serum

TME : Tumor microenvironment

\section{Introduction}

Eosinophilic pleural effusion (EPE) is defined as pleural fluid with a nucleated cell count containing $10 \%$ or more eosinophils [1]. It is estimated that approximately $10 \%$ of exudative pleural effusions are eosinophilic [1]. Causes of EPE include pleuritis, trauma (e.g., pneumothorax, hemothorax, thoracic surgery), and malignancies. According to a meta-analysis of 687 cases of EPE, the most common cause was malignancy (26\%), followed by idiopathic (25\%) and pneumonia (13\%) [2].

On the other hand, it has been shown that tumor-related eosinophilia may have extended survival benefits for some cancer patients [3-5]. In recent years, it has been demonstrated that peripheral blood eosinophils before administration are a potential predictive marker for a beneficial clinical response in cancer immunotherapy, particularly immune checkpoint inhibitors [6-11]. This finding suggested malignant pleural effusion (MPE) is an essential tool for investigating the tumor microenvironment (TME). In a previous prospective study, the survival of patients with EPE was better than that of patients with non-EPE [1]. However, there has been no study on the prognosis difference between EPE and non-EPE in lung cancer patients. Therefore, in this study, we investigated the prognosis difference between EPE and non-EPE due to lung cancer.

\section{Materials and methods}

\section{Patients}

We retrospectively reviewed all patients diagnosed with lung cancer who presented with malignant pleural effusion between May 2007 and September 2020 at the National Hospital Organization Kochi Hospital. Only patients with malignant cells confirmed in the pleural fluid or pleural biopsy were included to maintain study quality. We performed conventional cytology examination or histological analyses independently to identify malignant cells in the effusion fluid or pleural biopsy tissue. For conventional cytologic examination, $5 \sim 10 \mathrm{~mL}$ of effusion fluid obtained by diagnostic thoracentesis was centrifuged at $2500 \mathrm{rpm}$ for $10 \mathrm{~min}$. We prepared a minimum of two thin smears from the sediment. According to the hospital pathology laboratory's standard protocol, one smear was air-dried and stained with Leishman-Giemsa stain. The other smear was immediately fixed in 95\% alcohol and stained with Papanicolaou stain. For the histological analysis, tissue specimens obtained during the pleural biopsy were processed after formalin fixation, and the sections were stained with hematoxylin-eosin dye. The institutional review board of the National Hospital Organization Kochi Hospital approved the study protocol. Informed consent was waived because of the retrospective nature of the study.

\section{Statistical analysis}

Categorical and continuous variables are summarized using descriptive statistics. The independent-samples $t$ test was used to test for differences between continuous variables. The Pearson's chi-squared test and Fisher's exact test were used to test for associations between categorical variables. Overall survival (OS) was evaluated as the period from the day when pleural effusion was collected to the day of death from any cause using the Kaplan-Meier method. The log-rank test was used to compare survival curves. A Cox proportional hazards model was used to estimate the hazard ratio (for eosino $\geq 10 \%$ compared with eosino $<10 \%$ ) with a $95 \%$ confidence interval (CI). All statistical analyses were performed using EZR (developed in 2012 by Y. Kanda, Saitama Medical Center, Jichi Medical University), a graphical user interface in $\mathrm{R}$ (version 3.6.3, R Foundation for Statistical Computing, Vienna, Austria) or SPSS statistics version 27.0 (IBM, Armonk, USA). P-values are presented without adjusting for multiple comparisons in an exploratory manner.

\section{Results}

\section{Patient characteristics}

A total of 152 lung cancer patients with MPE were included in the study. Among the 152 patients, 20 patients had EPE. The clinical characteristics of the enrolled patients are summarized in Table 1. Among the 152 patients, the mean age at diagnosis was 74.4 years (range 37-101), 89 patients (59\%) were male, and 67 patients $(44 \%)$ were former or current smokers. The majority of patients had an Eastern 
Table 1 Characteristics of the study population

\begin{tabular}{|c|c|c|c|c|c|}
\hline & & $\begin{array}{l}\text { Total } \\
\mathrm{n}=152\end{array}$ & $\begin{array}{l}\text { Eosino } \geq 10 \% \\
n=20\end{array}$ & $\begin{array}{l}\text { Eosino }<10 \% \\
n=132\end{array}$ & $\mathrm{p}$ \\
\hline \multirow[t]{3}{*}{ Age } & Mean age, years (range) & $74.4(37-101)$ & $71.4(37-101)$ & $74.8(45-100)$ & $0.10^{*}$ \\
\hline & $\geq 65(\%)$ & $126(82)$ & $16(80)$ & $110(83)$ & \\
\hline & $<65(\%)$ & $26(17)$ & $4(20)$ & $22(17)$ & \\
\hline \multirow[t]{2}{*}{$\operatorname{Sex}(\%)$} & Male & $89(59)$ & $11(55)$ & $78(59)$ & $0.81 * *$ \\
\hline & Female & $63(41)$ & $9(45)$ & $54(41)$ & \\
\hline \multirow[t]{3}{*}{ Smoking history (\%) } & Yes & $67(44)$ & $10(50)$ & $58(44)$ & $0.82 * * *$ \\
\hline & No & $63(41)$ & $7(35)$ & $56(42)$ & \\
\hline & Missing & $22(14)$ & $3(15)$ & $18(14)$ & \\
\hline \multirow[t]{5}{*}{ ECOG PS (\%) } & 0 & $19(12)$ & $3(15)$ & $16(12)$ & $0.76 * * *$ \\
\hline & 1 & $121(80)$ & $17(85)$ & 104 (79) & \\
\hline & 2 & $7(5)$ & $0(0)$ & $7(5)$ & \\
\hline & 3 & $2(1)$ & $0(0)$ & $2(2)$ & \\
\hline & 4 & $3(2)$ & $0(0)$ & $3(2)$ & \\
\hline pLHD & $\begin{array}{l}\text { Mean, IU/L } \\
\text { (range) }\end{array}$ & $\begin{array}{l}719 \\
(81-13200)\end{array}$ & $\begin{array}{l}538.9 \\
(136-2287)\end{array}$ & $\begin{array}{l}746.5 \\
(81-13200)\end{array}$ & $0.26^{*}$ \\
\hline sNLR & $\begin{array}{l}\text { Ratio } \\
\text { (range) }\end{array}$ & $\begin{array}{l}6.75 \\
(0.96-66.62)\end{array}$ & $\begin{array}{l}7 \\
(1.17-66.62)\end{array}$ & $\begin{array}{l}6.71 \\
(0.96-63.74)\end{array}$ & $0.34 *$ \\
\hline \multirow[t]{4}{*}{ Histologic type (\%) } & Adeno & $125(82)$ & $18(90)$ & $107(81)$ & $0.36 * * *$ \\
\hline & Squamous & $6(4)$ & $1(5)$ & $5(4)$ & \\
\hline & Small & $11(7)$ & $0(0)$ & $11(8)$ & \\
\hline & Others & $10(7)$ & $1(5)$ & $9(7)$ & \\
\hline \multirow[t]{2}{*}{ Driver mutation (\%) } & EGFR & $27(18)$ & $1(5)$ & $26(20)$ & $0.20 * *$ \\
\hline & ALK & $1(1)$ & $1(5)$ & $0(0)$ & $0.13 * *$ \\
\hline \multirow[t]{2}{*}{ Pleurodesis (\%) } & Yes & $59(39)$ & $9(45)$ & $50(38)$ & $0.63 * *$ \\
\hline & No & $93(61)$ & $11(55)$ & $82(62)$ & \\
\hline \multirow[t]{2}{*}{ Treatment $(\%)$} & Supportive & $52(34)$ & $6(30)$ & $46(35)$ & $1.00 * *$ \\
\hline & Systemic chemotherapy & $100(66)$ & $14(70)$ & $86(65)$ & \\
\hline
\end{tabular}

ECOG PS, Eastern Cooperative Oncology Group Performance Status; pLHD, pleural fluid lactate dehydrogenase; sNLR, neutrophil-to-lymphocyte ratio in the serum; EGFR, epidermal growth factor receptor; ALK, anaplastic lymphoma kinase

*Independent-samples $t$ test; ** Fisher's exact test; *** Chi-squared test
Cooperative Oncology Group (ECOG) Performance Status (PS) of 0-1 (92\%) and exhibited adenocarcinoma histology $(82 \%)$. Twenty-seven patients were harboring epidermal growth factor receptor (EGFR) mutations and received EGFR-tyrosine kinase inhibitors. Fifty-nine patients (39\%) received pleurodesis. Among the patients, 34\% and $66 \%$ received supportive care only and active treatment, respectively.

Among the 20 patients with EPE, the mean age at diagnosis was 71.4 years (range 37-101), 11 patients (55\%) were male, and 10 patients $(50 \%)$ were former or current smokers. All patients had an ECOG PS of 0-1, and 18 patients $(90 \%)$ exhibited adenocarcinoma histology. Only one patient was harboring EGFR mutations and received EGFR-tyrosine kinase inhibitors. Also, only one patient was harboring anaplastic lymphoma kinase (ALK) rearrangement and received ALK-tyrosine kinase inhibitors. Nine patients $(45 \%)$ received pleurodesis. Among the patients, $30 \%$ and $70 \%$ received supportive care only and active treatment, respectively.

Among the 132 patients with non-EPE, the mean age at diagnosis was 74.8 years (range 45-100), 78 patients (59\%) were male, and 58 patients $(44 \%)$ were former or current smokers. The majority of patients had an ECOG PS of 0-1 (91\%) and exhibited adenocarcinoma histology $(81 \%)$. Of the 132 patients with non-EPE lung cancer, older patients, small cell carcinoma and EGFR mutations appeared to be slightly more common than EPE. However, there was no significant difference in patient characteristics between lung cancer patients with EPE and non-EPE. Furthermore, there was no bias in the presence or absence of active treatment in both groups. 


\section{OS of all lung cancer patients with MPE}

The OS of all 152 lung cancer patients with MPE was 298 days (95\% CI: 144-661) (Fig. 1).

\section{OS of lung cancer patients with EPE and non-EPE}

The OS of lung cancer patients with EPE $(n=20)$ and nonEPE ( $n=132)$ was 766 days (95\% CI: 131-not reached) and 252 days (95\% CI: 88-368), respectively (Fig. 2). The OS of lung cancer patients with EPE was significantly longer than that with non-EPE $(\mathrm{P}=0.035)$.

\section{OS of lung cancer patients with MPE according to the ECOG PS}

The OS of PSO $(n=19)$ lung cancer patients with MPE, PS1 $(n=121)$, and PS2 $4(n=11)$ were 345 days $(95 \% \mathrm{CI}$ : 171-1162), 323 days (95\% CI: 128-774), and 39 days (95\% CI: 6-not reached), respectively (Fig. 3). The OS of PS0/1 lung cancer patients with MPE was significantly longer than that of PS2-4 lung cancer patients with MPE $(\mathrm{P}<0.001)$.

\section{Patient survival according to sex}

The OS of female lung cancer patients $(n=63)$ and of male lung cancer patients $(n=89)$ was 723 days $(95 \% \mathrm{CI}$ : 293-871) and 131 days (95\% CI: 78-311), respectively

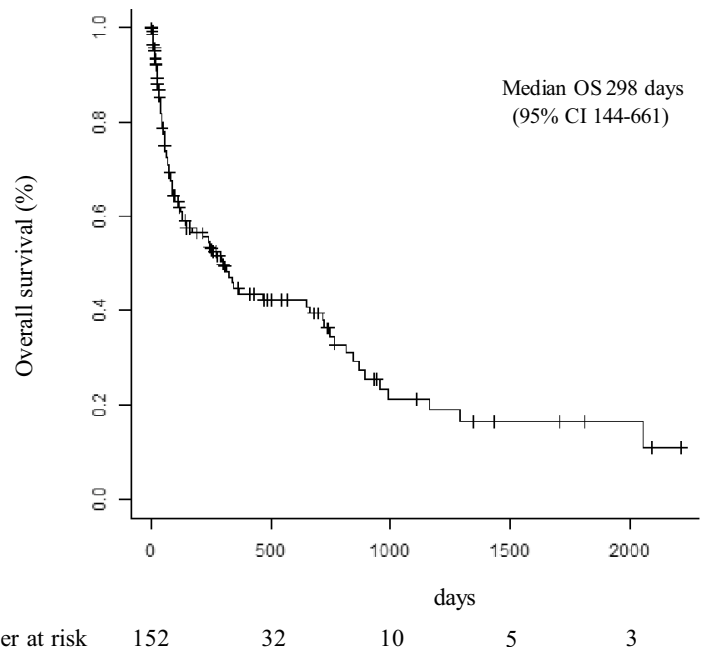

Fig. 1 Overall survival (OS) of all 152 lung cancer patients
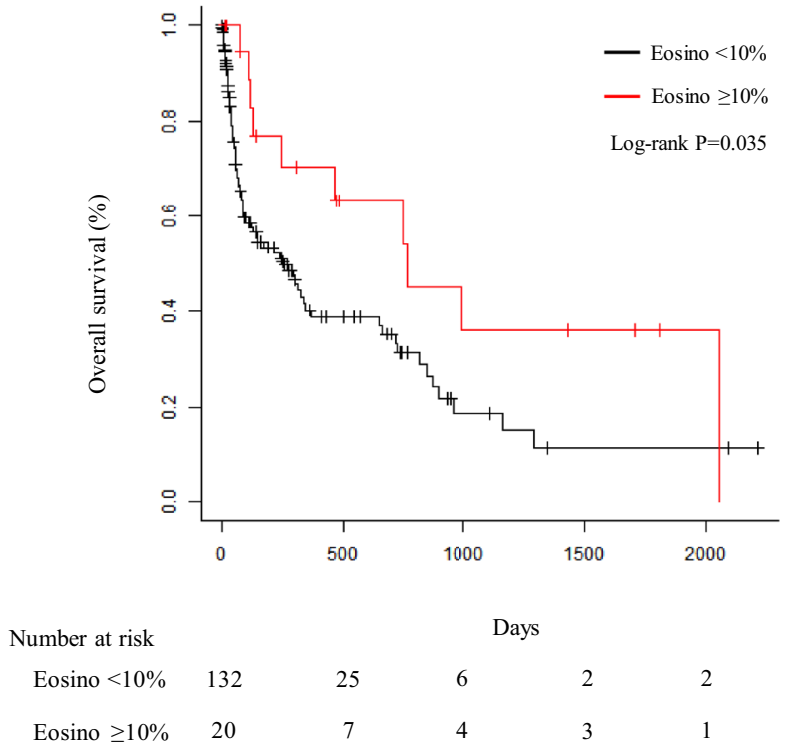

Fig. 2 Overall survival of patients with eosinophilic pleural effusion or non-eosinophilic pleural effusion

(Fig. 4). The OS of female lung cancer patients was significantly longer than that of male lung cancer patients $(\mathrm{P}<0.006)$.

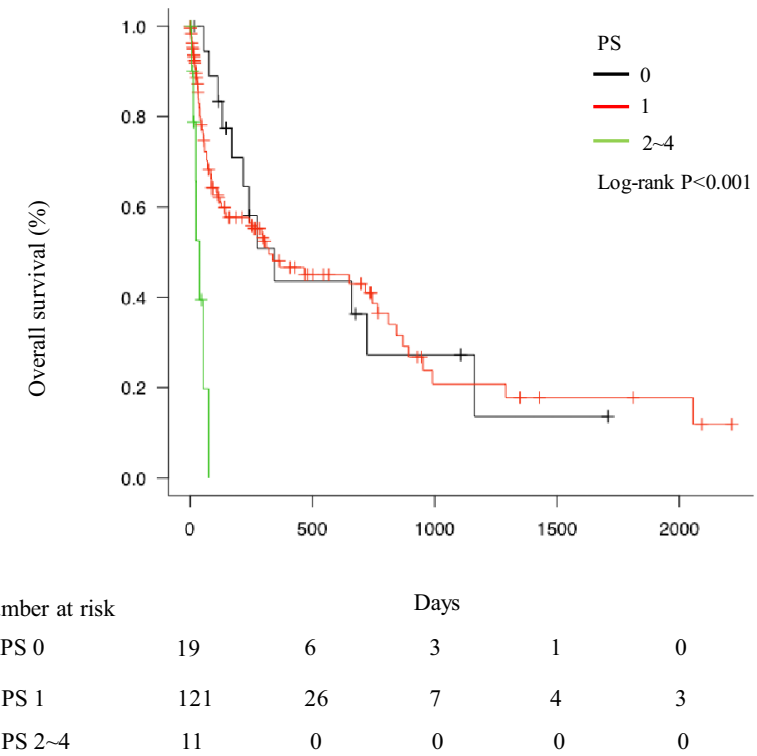

Fig. 3 Patient survival according to the ECOG PS 


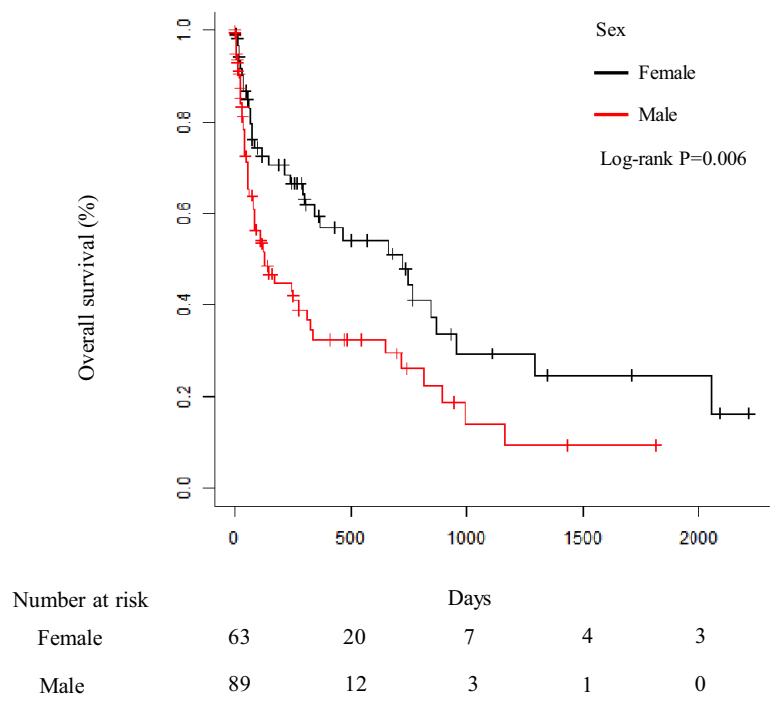

Fig. 4 Patient survival according to sex

Table 2 Cox proportional regression analysis of statically significant prognostic factors (by univariate analysis) for the survival of 152 patients

\begin{tabular}{lllc}
\hline Factors & Hazard ratios & $95 \%$ CI of HR & P-value \\
\hline Eosino $\geq 10 \%$ & 0.45 & $0.22-0.92$ & 0.02 \\
ECOG PS & 4.29 & $1.08-10.20$ & $<0.001$ \\
Sex & 1.72 & $1.08-2.74$ & 0.02 \\
sNLR & 1.07 & $1.04-1.10$ & $<0.001$ \\
NSCLC & 1.76 & $0.79-3.91$ & 0.16 \\
\hline
\end{tabular}

ECOG PS, Eastern Cooperative Oncology Group Performance Status; sNLR, neutrophil-to-lymphocyte ratio in the serum; NSCLC, non-small-cell lung cancer

\section{Multivariate analysis}

A Cox proportional regression analysis showed that eosino $\geq 10 \%$, ECOG PS, sex, and the neutrophil-to-lymphocyte ratio in the serum (sNLR) may be independent prognostic factors affecting the survival of patients with MPE (Table 2). The histological type was not associated with the prognosis.

\section{Discussion}

Our study demonstrates that lung cancer patients with EPE have a better prognosis than those with non-EPE. To our knowledge, this is the first study to show a better prognosis of malignant EPE in lung cancer patients.
EPE is defined as pleural fluid with a nucleated cell count containing $10 \%$ or more eosinophils [1]. It is considered that about $10 \%$ of exudative pleural effusion is EPE [1]. Causes of EPE include pleuritis, trauma (e.g., pneumothorax, hemothorax, thoracic surgery), and malignancies. In a meta-analysis of 687 cases of EPE, the most common cause was malignant tumors (26\%), followed by idiopathic (25\%) and pneumonia (13\%) [2]. On the other hand, the frequency of EPE (about 2.3-6.8\%) was not as high in MPE [12, 13]. However, in EPE, the frequency of malignant tumors was $6-40 \%[1,14,15]$. Malignant tumors are found in EPE as often as in non-EPE [1]. Lung cancer is the most common malignant tumor associated with EPE [14, 15]. In a review of $135 \mathrm{EPE}$ cases, 47 were associated with malignancies, 23 of which were associated with lung cancer [15].

Pleural fluid lactate dehydrogenase, histology of the primary tumor, ECOG PS, and sNLR have been reported to be predictors of survival in patients with malignant pleural effusion [16-19]. In our study, a multivariable analysis confirmed that eosino $\geq 10 \%(\mathrm{P}=0.02)$, $\mathrm{PS}(\mathrm{P}<0.001)$, sex $(\mathrm{P}=0.02)$, and sNLR $(\mathrm{P}<0.001)$ may be independent predictors of OS. In previous reports, female lung cancer patients with MPE had a favorable prognosis [18, 19]. These results are consistent with previous studies. Eighteen females and nine males harbored EGFR mutations, and more female lung cancer patients harbored EGFR mutations than males $(\mathrm{P}<0.001)$. Lung cancer patients harboring EGFR mutations have a good prognosis (results not shown), which may have influenced the prognosis in females. However, there have been no reports of good prognosis for EPE in lung cancer patients. We demonstrate for the first time that lung cancer patients with EPE have a better prognosis than those with non-EPE.

In recent years, the relationship between eosinophils and cancer has attracted attention due to cancer immunotherapies such as immune checkpoint inhibitors. Although the functional role of eosinophils in human cancer is not fully understood, many studies have shown that tumor-related eosinophilia may provide survival benefits to cancer patients [3-5]. In oral squamous epithelial cancer, nasopharyngeal cancer [20], esophageal cancer [21], colorectal cancer [22, 23], lung cancer [24], laryngeal cancer, bladder cancer [25], prostate cancer [26], and penis cancer [27], similar findings have been reported. The prognosis was good when there was eosinophil infiltration into the tissue and eosinophil degranulation in the tumor tissue. Good prognosis with eosinophils is also independent of common prognostic factors (stage, age, sex, drinking history, smoking history, histological grading, angiogenesis, vascular infiltration, and nerve infiltration). Interestingly, this findings becomes significant in the subgroup of patients with poor prognosis [20]. On the other hand, tumor-related tissue eosinophil infiltration is a poor prognostic factor in Hodgkin lymphoma [28]. In a 
knockout model, tumor-related tissue eosinophil infiltration was a risk factor for oral cancer [29]. Eosinophils have been suggested to play pleiotropic and opposing roles in the TME [30-32].

In humans, peripheral blood eosinophilia often occurs when immunotherapy with interleukin (IL)-2 [33, 34], IL-4 [35], granulocyte macrophage colony-stimulating factor [36], or tumor vaccine is performed [37]. Intrapleural administration of IL-2 is also known to cause significant eosinophilic pleural effusion [38]. In recent years, it has been shown that the number of peripheral blood eosinophils before administration is a valuable marker for predicting the effect when using cancer immunotherapies, especially immune checkpoint inhibitors [6-11]. Eosinophils infiltrate the tumor, and their activation there helps T cells infiltrate the tumor as well $[4,39]$. It has also been reported that activated eosinophils promote tumor-specific $\mathrm{CD} 8^{+} \mathrm{T}$ cell infiltration and tumor rejection and also prolong survival by improving the TME [39].

Activated innate lymphoid cell populations accumulate in human tumor tissues [40]. It has been suggested that lung group 2 innate lymphoid cells (ILC2), which produce IL-5 or IL-13 in response to IL-25 and IL-33, suppress the lung metastasis of cancer cells [41]. Tissue-specific ILC2 infiltrate pancreatic ductal adenocarcinomas to activate tissuespecific tumor immunity, and increased tissue infiltrates of ILC2 correlate with prolonged survival [42]. Eosinophils and LC2 may be important cells that modulate innate and adaptive immunity. Pleural fluid eosinophilia only has a weak correlation with peripheral blood eosinophilia (results not shown). Since eosinophils in the pleural effusion are not normal cells of the lung or pleural tissue, the development of EPE requires the recruitment of eosinophils from the bone marrow [43]. The mechanism of eosinophil recruitment into the pleural space has not yet been fully elucidated. However, cytokines, chemokines, and adhesion molecules are known to be involved. The involvement of ILC2 has also been suggested [44]. Furthermore, it has been reported that ILC2 is present in human MPE and produces type 2 cytokines such as IL-4, IL-5, and IL-13 [45].

The limitation of this study is that it is a single-center retrospective analysis conducted with heterogeneous data regarding patient cohorts. Therefore, the study results are speculative and not definitive. Furthermore, the observation period is 14 years, and advances in treatment may affect the results. However, in previous reports, talc pleurodesis and active treatment were not factors for better survival in MPE patients [17, 19]. In our study, patients with active treatment have a better prognosis than those with supportive care only (results not shown). However, there was no treatment bias between EPE and non-EPE patients. Additionally, active treatment was excluded from the multivariate analysis variables. Finally, the frequency of EPE was not very high in malignant pleural effusions. Overall, a prospective controlled study with multiple centers is needed to confirm our conclusions.

Although we should consider these limitations when interpreting our study, this is the first study showing a better prognosis of lung cancer patients with EPE. The mechanism of the onset of malignant EPE has not yet been fully elucidated, although it is known that host-tumor cell interactions cause eosinophilic pleural effusion. Furthermore, eosinophils may play an essential role in the modulation of innate and adaptive immunity. In general, the relationship between eosinophils and cancer immunology needs further elucidation.

\section{Conclusion}

In conclusion, we demonstrate that lung cancer patients with EPE have a better prognosis than those with non-EPE. In recent years, the relationship between eosinophils and cancer has attracted attention due to cancer immunotherapy, but further progress in basic and clinical cancer research in this field is required.

Acknowledgements We thank Hiroki Yoshida for statistical advice.

Author contribution Conceptualization and design: [Eiji Takeuchi]; Data collection and analysis: [Yoshio Okano], [Hisanori Machida], [Katsuhiro Atagi], [Yoshihiro Kondou], [Naoki Kadota], [Nobuo Hatakeyama], [Tsutomu Shinohara], and [Keishi Naruse]; Formal analysis and investigation: [Hisanori Machida]; Writing-original draft preparation: [Yoshio Okano]; Writing-review and editing: [Eiji Takeuchi]; Supervision: [Tsutomu Shinohara]. All authors read and approved the final manuscript.

\section{Declaration}

Conflict of interest statement The authors declare no conflicts of interest.

Ethical approval The institutional review board of the National Hospital Organization Kochi Hospital approved the study protocol (R2-13). Informed consent was waived because of the retrospective nature of the study.

Open Access This article is licensed under a Creative Commons Attribution 4.0 International License, which permits use, sharing, adaptation, distribution and reproduction in any medium or format, as long as you give appropriate credit to the original author(s) and the source, provide a link to the Creative Commons licence, and indicate if changes were made. The images or other third party material in this article are included in the article's Creative Commons licence, unless indicated otherwise in a credit line to the material. If material is not included in the article's Creative Commons licence and your intended use is not permitted by statutory regulation or exceeds the permitted use, you will need to obtain permission directly from the copyright holder. To view a copy of this licence, visit http://creativecommons.org/licenses/by/4.0/. 


\section{References}

1. Rubins JB, Rubins HB (1996) Etiology and prognostic significance of eosinophilic pleural effusions. Prospect Study Chest 110:1271-1274. https://doi.org/10.1378/chest.110.5.1271

2. Oba Y, Abu-Salah T (2012) The prevalence and diagnostic significance of eosinophilic pleural effusions: a meta-analysis and systematic review. Respiration 83:198-208. https://doi.org/10. 1159/000327200

3. Gatault S, Legrand F, Delbeke M, Loiseau S, Capron M (2012) Involvement of eosinophils in the anti-tumor response. Cancer Immunol Immunother 61:1527-1534. https://doi.org/10.1007/ s00262-012-1288-3

4. Davis BP, Rothenberg ME (2014) Eosinophils and cancer. Cancer. Immunol Res 2:1-8. https://doi.org/10.1158/2326-6066. CIR-13-0196

5. Varricchi G, Galdiero MR, Loffredo S, Lucarini V, Marone G, Mattei F, Marone G, Schiavoni G (2018) Eosinophils: The unsung heroes in cancer? Oncoimmunology 7:e1393134. https://doi.org/ 10.1080/2162402X.2017.1393134

6. Heppt MV, Heinzerling L, Kähler KC et al (2017) Prognostic factors and outcomes in metastatic uveal melanoma treated with programmed cell death-1 or combined PD-1/cytotoxic T-lymphocyte antigen-4 inhibition. Eur J Cancer 82:56-65. https://doi.org/10. 1016/j.ejca.2017.05.038

7. Moreira A, Leisgang W, Schuler G, Heinzerling L (2017) Eosinophilic count as a biomarker for prognosis of melanoma patients and its importance in the response to immunotherapy. Immunotherapy 9:115-121. https://doi.org/10.2217/imt-2016-0138

8. Gebhardt C, Sevko A, Jiang H et al (2015) Myeloid Cells and Related Chronic Inflammatory Factors as Novel Predictive Markers in Melanoma Treatment with Ipilimumab. Clin Cancer Res 21:5453-5459. https://doi.org/10.1158/1078-0432.CCR-15-0676

9. Weide B, Martens A, Hassel JC et al (2016) Baseline Biomarkers for Outcome of Melanoma Patients Treated with Pembrolizumab. Clin Cancer Res 22:5487-5496. https://doi.org/10.1158/10780432.CCR-16-0127

10. Tanizaki J, Haratani K, Hayashi H et al (2018) Peripheral Blood Biomarkers Associated with Clinical Outcome in Non-Small Cell Lung Cancer Patients Treated with Nivolumab. J Thorac Oncol 13:97-105. https://doi.org/10.1016/j.jtho.2017.10.030

11. Chu X, Zhao J, Zhou J et al (2020) Association of baseline peripheral-blood eosinophil count with immune checkpoint inhibitorrelated pneumonitis and clinical outcomes in patients with nonsmall cell lung cancer receiving immune checkpoint inhibitors. Lung Cancer 150:76-82. https://doi.org/10.1016/j.lungcan.2020. 08.015

12. Hirsch A, Ruffie P, Nebut M, Bignon J, Chretien J (1979) Pleural effusion: laboratory tests in 300 cases. Thorax 34:106-112. https://doi.org/10.1136/thx.34.1.106

13. Light RW, Erozan YS, Ball WC Jr (1973) Cells in pleural fluid. Their value in differential diagnosis. Arch Intern Med 132:854-860

14. Adelman M, Albelda SM, Gottlieb J, Haponik EF (1984) Diagnostic utility of pleural fluid eosinophilia. Am J Med 77:915-920. https://doi.org/10.1016/0002-9343(84)90542-4

15. Krenke R, Nasilowski J, Korczynski P, Gorska K, Przybylowski T, Chazan R, Light RW (2009) Incidence and aetiology of eosinophilic pleural effusion. Eur Respir J 34:1111-1117. https://doi.org/ 10.1183/09031936.00197708

16. Clive AO, Kahan BC, Hooper CE et al (2014) Predicting survival in malignant pleural effusion: development and validation of the LENT prognostic score. Thorax 69:1098-1104. https://doi.org/ 10.1136/thoraxjnl-2014-205285
17. Anevlavis S, Kouliatsis G, Sotiriou I, Koukourakis MI, Archontogeorgis K, Karpathiou G, Giatromanolaki A, Froudarakis ME (2014) Prognostic factors in patients presenting with pleural effusion revealing malignancy. Respiration 87:311-316. https://doi. org/10.1159/000356764

18. Zamboni MM, Silva de CT, Baretta jr R, Cunha ET, Cardoso GP (2015) Important prognostic factors for survival in patients with malignant pleural effusion. BMC Pulm Med 15:29. https://doi.org/ 10.1186/s12890-015-0025-Z

19. Lee YS, Nam HS, Lim JH, Kim JS, Moon Y, Cho JH, Ryu JS, Kwak SM, Lee HL (2017) Prognostic impact of a new score using neutrophil-to-lymphocyte ratios in the serum and malignant pleural effusion in lung cancer patients. BMC Cancer 17:557. https:// doi.org/10.1186/s12885-017-3550-8

20. Fujii M, Yamashita T, Ishiguro R, Tashiro M, Kameyama K (2002) Significance of epidermal growth factor receptor and tumor associated tissue eosinophilia in the prognosis of patients with nasopharyngeal carcinoma. Auris Nasus Larynx 29:175-181. https://doi.org/10.1016/s0385-8146(01)00135-3

21. Ishibashi S, Ohashi Y, Suzuki T, Miyazaki S, Moriya T, Satomi S, Sasano H (2006) Tumor-associated tissue eosinophilia in human esophageal squamous cell carcinoma. Anticancer Res 26:1419-1424

22. Pretlow TP, Keith EF, Cryar AK, Bartolucci AA, Pitts AM, Pretlow TG 2nd, Kimball PM, Boohaker EA (1983) Eosinophil infiltration of human colonic carcinomas as a prognostic indicator. Cancer Res 43:2997-3000

23. Fernández-Aceñero MJ, Galindo-Gallego M, Sanz J, Aljama A (2000) Prognostic influence of tumor-associated eosinophilic infiltrate in colorectal carcinoma. Cancer 88:1544-1548

24. Takanami I, Takeuchi K, Gika M (2002) Immunohistochemical detection of eosinophilic infiltration in pulmonary adenocarcinoma. Anticancer Res 22:2391-2396

25. Costello R, O'Callaghan T, Sébahoun G (2005) Eosinophils and antitumour response. Rev Med Interne 26:479-484. https://doi. org/10.1016/j.revmed.2005.02.013

26. Luna-Moré S, Florez P, Ayala A, Diaz F, Santos A (1997) Neutral and acid mucins and eosinophil and argyrophil crystalloids in carcinoma and atypical adenomatous hyperplasia of the prostate. Pathol Res Pract 193:291-298. https://doi.org/10.1016/s03440338(97)80006-4

27. Ono Y, Ozawa M, Tamura Y, Suzuki T, Suzuki K, Kurokawa K, Fukabori Y, Yamanaka H (2002) Tumor-associated tissue eosinophilia of penile cancer. Int J Urol 9:82-87. https://doi.org/10. 1046/j.1442-2042.2002.00424.x

28. von Wasielewski R, Seth S, Franklin J, Fischer R, Hübner K, Hansmann ML, Diehl V, Georgii A (2000) Tissue eosinophilia correlates strongly with poor prognosis in nodular sclerosing Hodgkin's disease, allowing for known prognostic factors. Blood 95:1207-1213

29. da Silva JM, Queiroz-Junior CM, Batista AC, Rachid MA, Teixeira MM, Silva da TA (2014) Eosinophil depletion protects mice from tongue squamous cell carcinoma induced by 4-nitroquinoline-1-oxide. Histol Histopathol 29:387-396. https://doi.org/10. 14670/hh-29.387

30. Reichman H, Karo-Atar D, Munitz A (2016) Emerging roles for eosinophils in the tumor microenvironment. Trends Cancer 2:664-675. https://doi.org/10.1016/j.trecan.2016.10.002

31. Simon SCS, Utikal J, Umansky V (2019) Opposing roles of eosinophils in cancer. Cancer Immunol Immunother 68:823-833. https://doi.org/10.1007/s00262-018-2255-4

32. Grisaru-Tal S, Itan M, Klion AD, Munitz A (2020) A new dawn for eosinophils in the tumour microenvironment. Nat Rev Cancer 20:594-607. https://doi.org/10.1038/s41568-020-0283-9 
33. Huland E, Huland H (1992) Tumor-associated eosinophilia in interleukin-2-treated patients: evidence of toxic eosinophil degranulation on bladder cancer cells. J Cancer Res Clin Oncol 118:463-467. https://doi.org/10.1007/bf01629431

34. Simon HU, Plötz S, Simon D, Seitzer U, Braathen LR, Menz G, Straumann A, Dummer R, Levi-Schaffer F (2003) Interleukin-2 primes eosinophil degranulation in hypereosinophilia and wells' syndrome. Eur J Immunol 33:834-839. https://doi.org/10.1002/ eji.200323727

35. Sosman JA, Bartemes K, Offord KP et al (1995) Evidence for eosinophil activation in cancer patients receiving recombinant interleukin-4: effects of interleukin-4 alone and following interleukin-2 administration. Clin Cancer Res 1:805-812

36. Bristol JA, Zhu M, Ji H, Mina M, Xie Y, Clarke L, Forry-Schaudies S, Ennist DL (2003) In vitro and in vivo activities of an oncolytic adenoviral vector designed to express GM-CSF. Mol Ther 7:755-764. https://doi.org/10.1016/s1525-0016(03)00103-5

37. Schaefer JT, Patterson JW, Deacon DH, Smolkin ME, Petroni GR, Jackson EM, Slingluff CL Jr (2010) Dynamic changes in cellular infiltrates with repeated cutaneous vaccination: a histologic and immunophenotypic analysis. J Transl Med 8:79. https://doi.org/ 10.1186/1479-5876-8-79

38. Nakamura Y, Ozaki T, Yanagawa H, Yasuoka S, Ogura T (1990) Eosinophil colony-stimulating factor induced by administration of interleukin-2 into the pleural cavity of patients with malignant pleurisy. Am J Respir Cell Mol Biol 3:291-300. https://doi.org/ 10.1165/ajrcmb/3.4.291

39. Carretero R, Sektioglu IM, Garbi N, Salgado OC, Beckhove P, Hämmerling GJ (2015) Eosinophils orchestrate cancer rejection by normalizing tumor vessels and enhancing infiltration of CD8(+) T cells. Nat Immunol 16:609-617. https://doi.org/10. 1038/ni.3159
40. Salimi M, Wang R, Yao X et al (2018) Activated innate lymphoid cell populations accumulate in human tumour tissues. BMC Cancer 18:341. https://doi.org/10.1186/s12885-018-4262-4

41. Ikutani M, Yanagibashi T, Ogasawara M et al (2012) Identification of innate IL-5-producing cells and their role in lung eosinophil regulation and antitumor immunity. J Immunol 188:703-713. https://doi.org/10.4049/jimmunol.1101270

42. Moral JA, Leung J, Rojas LA et al (2020) ILC2s amplify PD-1 blockade by activating tissue-specific cancer immunity. Nature 579:130-135. https://doi.org/10.1038/s41586-020-2015-4

43. Heidecker J, Kaplan A, Sahn SA (2006) Pleural fluid and peripheral eosinophilia from hemothorax: hypothesis of the pathogenesis of EPE in hemothorax and pneumothorax. Am J Med Sci 332:148-152. https://doi.org/10.1097/00000441-20060 9000-00011

44. Kwon BI, Hong S, Shin K, Choi EH, Hwang JJ, Lee SH (2013) Innate type 2 immunity is associated with eosinophilic pleural effusion in primary spontaneous pneumothorax. Am J Respir Crit Care Med 188:577-585. https://doi.org/10.1164/rccm. 201302-0295OC

45. Tumino N, Martini S, Munari E et al (2019) Presence of innate lymphoid cells in pleural effusions of primary and metastatic tumors: Functional analysis and expression of PD-1 receptor. Int J Cancer 145:1660-1668. https://doi.org/10.1002/ijc.32262

Publisher's Note Springer Nature remains neutral with regard to jurisdictional claims in published maps and institutional affiliations. 